\title{
Neuroautonomic evaluation of patients with unexplained syncope: incidence of complex neurally mediated diagnoses in the elderly
}

\section{Martina Rafanelli \\ Alessandro Morrione \\ Annalisa Landi \\ Emilia Ruffolo \\ Valentina M Chisciotti \\ Maria A Brunetti \\ Niccolò Marchionni \\ Andrea Ungar}

Syncope Unit, Cardiology and Geriatric Medicine, University of Florence and Azienda OspedalieroUniversitaria Careggi, Florence, Italy

\section{Video abstract}

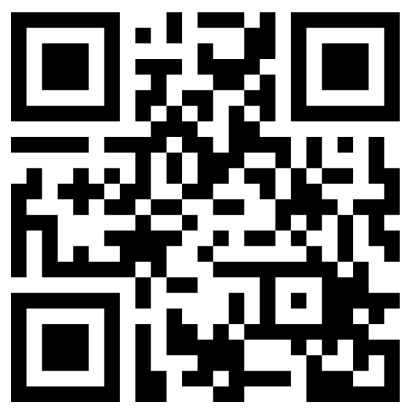

Point your SmartPhone at the code above. If you have a QR code reader the video abstract will appear. Or use: http://dvpr.es/lexyzbe
Correspondence: Andrea Ungar Syncope Unit, Cardiology and Geriatric Medicine, University of Florence and Azienda Ospedaliero-Universitaria Careggi, Viale Pieraccini 6,

Florence 50139 , Italy

Tel +3905 $5427 \quad 1467$

Fax +3905 $5427 \quad 1469$

Email aungar@unifi.it
This article was published in the following Dove Press journal:

Clinical Interventions in Aging

14 February 2014

Number of times this article has been viewed

Background: The incidence of syncope increases in individuals over the age of 70 years, but data about this condition in the elderly are limited. Little is known about tilt testing (TT), carotid sinus massage (CSM), or supine and upright blood pressure measurement related to age or about patients with complex diagnoses, for example, those with a double diagnosis, ie, positivity in two of these three tests.

Methods: A total of 873 consecutive patients of mean age $66.5 \pm 18$ years underwent TT, CSM, and blood pressure measurement in the supine and upright positions according to the European Society of Cardiology guidelines on syncope. ${ }^{1}$ Neuroautonomic evaluation was performed if the first-line evaluation (clinical history, physical examination, electrocardiogram) was suggestive of neurally mediated syncope, or if the first-line evaluation was suggestive of cardiac syncope but this diagnosis was excluded after specific diagnostic tests according to European Society of Cardiology guidelines on syncope, or if certain or suspected diagnostic criteria were not present after the first-line evaluation.

Results: A diagnosis was reached in $64.3 \%$ of cases. TT was diagnostic in $50.4 \%$ of cases, CSM was diagnostic in $11.8 \%$ of cases, and orthostatic hypotension was present in $19.9 \%$ of cases. Predictors of a positive tilt test were prodromal symptoms and typical situational syncope. Increased age and a pathologic electrocardiogram were predictors of carotid sinus syndrome. Varicose veins and alpha-receptor blockers, nitrates, and benzodiazepines were associated with orthostatic hypotension. Twenty-three percent of the patients had a complex diagnosis. The most frequent association was between vasovagal syncope and orthostatic hypotension $(15.8 \%) ; 42.9 \%$ of patients aged 80 years or older had a complex diagnosis, for which age was the strongest predictor.

Conclusion: Neuroautonomic evaluation is useful in older patients with unexplained syncope after the initial evaluation. A complex neurally mediated diagnosis is frequent in older people. Our results suggest that complete neuroautonomic evaluation should be done particularly in older patients.

Keywords: syncope, elderly, tilt testing, carotid sinus massage, blood pressure, neurally mediated diagnosis

\section{Introduction}

Syncope is a transient loss of consciousness due to transient global cerebral hypoperfusion, characterized by rapid onset, short duration, spontaneous and complete recovery. ${ }^{1}$ With an incidence of at least $6 \%$ per year, a prevalence of $10 \%$ (increasing to $23 \%$ in institutionalized elderly populations), and a $33 \%$ recurrence rate at 2 years, syncope is recognized as an important clinical challenge in older people. ${ }^{2}$ Despite growing evidence-based information guiding standardized approaches to syncope 
and the exponentially increased incidence of syncope after the age of 70 years, data on this condition in the "older elderly" are still limited. In particular, little is known about the neuroautonomic evaluation (tilt testing [TT], carotid sinus massage [CSM], supine and upright blood pressure $[\mathrm{BP}]$ measurement) related to age and about patients with a complex diagnosis, ie, those who show positivity in two of the above three tests. The present study, carried out in consecutive patients referred to our geriatric syncope unit, aimed to evaluate the diagnostic power of the neuroautonomic evaluation, to identify age-related predictors of reflex syncope, and to investigate the possibility of a complex diagnosis in relation to advancing age.

\section{Materials and methods}

This study was carried out in 873 patients who were consecutively referred to the Syncope Unit, Cardiology and Geriatric Medicine, Azienda Ospedaliero-Universitaria Careggi, Florence, between July 2002 and September 2007. Patients were referred from the emergency department, as inpatients or on an outpatient basis by a general practitioner. All patients underwent an initial assessment before neuroautonomic evaluation. The neuroautonomic evaluation (TT, CSM, and BP measurement in the supine and upright position) was performed according to European Society of Cardiology (ESC) guidelines. ${ }^{1}$ We enrolled all consecutive patients for a complete neuroautonomic evaluation.

Indications for neuroautonomic evaluation were: first-line evaluation (clinical history, physical examination, electrocardiogram [ECG]) suggesting neurally mediated syncope; first-line evaluation suggesting cardiac syncope, already excluded after specific diagnostic tests according to ESC guidelines on syncope, ${ }^{1}$ no certain or suspected diagnostic criteria after the first-line evaluation.

\section{Diagnostic protocol}

Each patient referred to our syncope unit underwent initial evaluation by a careful clinical history searching for the presence of comorbidities (hypertension, diabetes, heart disease, varicose veins), characteristics of syncope (rate, prodromes, situational syncope, unexplained falls, injuries), and drugs consumed. An ECG and a complete physical examination were also performed. If a cardiogenic cause of syncope was suspected, all tests needed to exclude this were performed before the neuroautonomic evaluation according to the ESC guidelines on syncope. ${ }^{1}$ If the first-line evaluation was suggestive of neurally mediated syncope, TT, CSM, supine and upright BP measurement were performed.

TT was performed using the Italian protocol, previously validated in older patients, ${ }^{3,4}$ under continuous ECG and systemic BP (Task Force ${ }^{\circledR}$ monitor, CNSystems Medizintechnik AG, Graz, Austria) monitoring. Briefly, the test consists of 20 minutes of passive orthostatic position at an angle of $60^{\circ}$ that is potentiated if syncope does not occur on administration of sublingual nitroglycerin $(400 \mu \mathrm{g})$ with a further 15 minutes of observation at the same angle. The test was considered positive if symptoms reproducing those reported by the patient during the syncopal episode were accompanied by hypotension, bradycardia, or both. ${ }^{5}$

CSM was performed according to the "method of symptoms" technique. ${ }^{6}$ Transient ischemic attack or stroke in the 3 months beforehand or critical carotid artery stenosis on Doppler ultrasonography performed in the presence of carotid bruits were contraindications to CSM. ${ }^{7}$

Orthostatic syncope is diagnosed when there is documentation of orthostatic hypotension associated with syncope or presyncope. Orthostatic BP measurement is recommended after 5 minutes of lying supine, and at each minute (or more often) while standing for 3 minutes. Measurement may be continued for longer if BP is still falling after 3 minutes. If the patient does not tolerate standing for this period, the lowest systolic BP during the upright position should be recorded. The test is diagnostic when there is a symptomatic fall in systolic BP from the baseline value $\geq 20 \mathrm{mmHg}$ or diastolic $\mathrm{BP} \geq 10 \mathrm{mmHg}$ or a decrease in systolic BP to $<90 \mathrm{mmHg}$ (class I level $\mathrm{C}$ ), and should be considered diagnostic when there is an asymptomatic fall in systolic BP from baseline value $\geq 20 \mathrm{mmHg}$ or diastolic $\mathrm{BP} \geq 10 \mathrm{mmHg}$ or a decrease in systolic BP to $<90 \mathrm{mmHg}$ (class IIa, level C). ${ }^{1}$

\section{Definitions}

Based on the ESC guidelines, ${ }^{1}$ syncope was classified as:

- Neurally mediated, including vasovagal syncope (emotion-induced or orthostatic stress-mediated, usually preceded by prodromal symptoms like sweating, pallor, and nausea); situational syncope, traditionally refers to reflex syncope associated with specific circumstances, post-exercise, post-defecation, and post-micturition syncope; an atypical form (when reflex syncope occurs with uncertain or even apparently in the absence of triggers, with the diagnosis based on exclusion of other causes and on reproducing similar symptoms with TT); and carotid sinus syncope, triggered by mechanical 
manipulation of the carotid sinuses (in the most common type, no mechanical trigger is found and it is diagnosed by $\mathrm{CSM}$ ).

- Orthostatic syncope, when syncope is associated with orthostatic hypotension.

A written informed consent to perform neuroautonomic evaluation was obtained from each patient. Italian legislation concedes that, in the case of retrospective studies, where no intervention is made on patients who give their written informed consent to use their clinical data, the ethics committee need only be informed and formal approval is not required.

\section{Statistical analysis}

All analyses were performed using Statistica version 8.0 (StatSoft Italia, Padova, Italy) and SPSS version 12.2 (SPSS Inc, Chicago, IL, USA). The Student's $t$-test for unpaired data was used to compare continuous data between groups, and Chi-squared or Fisher's Exact tests were used when appropriate to compare dichotomous variables. $P<0.05$ was considered to be statistically significant. The data are reported as the mean \pm standard deviation or as a percentage. Analysis of variance (ANOVA and post-hoc Duncan's test) was used to analyze the variation among and between decades. Moreover, a multivariate analysis of predictors of different diagnoses was performed by multiple logistic regression.
The hazard ratio (HR) is provided with its $95 \%$ confidence interval (CI).

\section{Results}

\section{Characteristics of study population}

The study population comprised 873 consecutive patients with at least one episode of syncope. In total, 373 men and 500 women of mean age $66.5 \pm 18$ years were enrolled; 584 patients were aged $\geq 65$ years (mean $77.2 \pm 7$ years) and $222(25.4 \%)$ were older than 80 years of age. The study group contained a majority of females, with greater comorbidity seen in older patients. Syncope caused injury in $36.3 \%$ of cases. Twenty-seven percent of the patients had a pathologic ECG (left or right bundle branch block, bifascicular block, left anterior bundle branch block, firstdegree atrioventricular block) and a large number of subjects received hypotensive therapy, especially older ones. Further, 684 patients $(78.4 \%)$ experienced approximately two episodes of syncope (Table 1).

\section{Results of neuroautonomic evaluation}

Neuroautonomic evaluation was diagnostic in 562 patients $(64.3 \%)$, both in the 187 patients aged $<65$ years $(64.7 \%)$ and in the 375 patients aged $\geq 65$ years $(64.2 \%$, $P=0.886$ ). A similar rate of diagnosis was obtained in the 222 patients older than 80 years $(n=140,63 \%)$. TT was

Table I Characteristics of the population

\begin{tabular}{|c|c|c|c|c|}
\hline & $\begin{array}{l}\text { All } \\
(n=873)\end{array}$ & $\begin{array}{l}\text { Age }<65 \text { years } \\
(n=289)\end{array}$ & $\begin{array}{l}\text { Age } \geq 65 \text { years } \\
(n=584)\end{array}$ & $P$ \\
\hline Mean age (years $\pm S D)$ & $66.5 \pm 18$ & $44.9 \pm 14$ & $77.2 \pm 7$ & - \\
\hline Male/female (n) & $373 / 500$ & $140 / 149$ & $233 / 351$ & - \\
\hline Hypertension, n (\%) & $451(51.6)$ & $77(26.6)$ & $374(64.0)$ & $<0.001$ \\
\hline Diabetes, n (\%) & $123(14)$ & $21(7.2)$ & $102(17.4)$ & $<0.001$ \\
\hline History of falls, n (\%) & $127(14.5)$ & II (3.8) & 116 (19.9) & $<0.001$ \\
\hline History of heart disease, n (\%) & I6I (I8.4) & $23(8.0)$ & $138(23.6)$ & $<0.001$ \\
\hline Varicose veins, n (\%) & $205(23.4)$ & $31(10.7)$ & I $74(29.8)$ & $<0.001$ \\
\hline Number of syncopes $(n \pm S D)$ & $5.5 \pm 7.6$ & $7.2 \pm 8.4$ & $4.8 \pm 7.1$ & $<0.001$ \\
\hline Single syncopal episode, n (\%) & $189(21.6)$ & $40(13.8)$ & $149(25.5)$ & $<0.001$ \\
\hline Presyncope, n (\%) & $283(32.4)$ & I0I (35.0) & $182(3||)$. & 0.261 \\
\hline Prodromes, n (\%) & $581(66.5)$ & $232(80.2)$ & $349(59.7)$ & $<0.001$ \\
\hline Situational syncope, n (\%) & $192(22)$ & $95(32.8)$ & $97(16.6)$ & $<0.001$ \\
\hline Injuries, n (\%) & $317(36.3)$ & $89(31.1)$ & $228(39.0)$ & 0.02 \\
\hline Hypotensive drugs, n (\%) & $458(52.4)$ & $72(24.9)$ & $386(66.1)$ & $<0.001$ \\
\hline ACEi/ARB, n (\%) & $349(40.0)$ & $53(18.3)$ & $296(50.6)$ & $<0.001$ \\
\hline Alpha-receptor blockers, n (\%) & $56(6.4)$ & $9(3.1)$ & $47(8.0)$ & 0.004 \\
\hline Nitrates, n (\%) & $59(6.7)$ & $3(1.0)$ & $56(9.6)$ & $<0.001$ \\
\hline Pathologic ECG, n (\%) & $236(27.0)$ & $35(12.1)$ & 201 (34.4) & $<0.001$ \\
\hline Patients with pacemaker, n (\%) & $19(2.1)$ & I (0.3) & $18(3.0)$ & $<0.001$ \\
\hline
\end{tabular}

Note: $P$-value represents a comparison of $<65$ years versus $\geq 65$ years.

Abbreviations: $A C E i$, angiotensin-converting enzyme inhibitors; ARB, angiotensin receptor blockers; SD, standard deviation. 
positive for vasovagal syncope in 440 patients $(50.4 \%)$, carotid sinus syndrome (CSS) was present in 103/873 patients $(11.8 \%)$, and orthostatic hypotension in $174 / 873$ patients $(19.9 \%)$.

Tilt test positivity was the same across the age groups, except in the second decade, where the rate of tilt test positivity was 90\% (Figure 1A). We analyzed the clinical characteristics of patients with a positive tilt test and compared them with those of patients with a negative tilt test; the mean age of the former group was lower than that of the latter group (65.1 \pm 18 years versus 67.9 \pm 17 years, respectively, $P=0.02$ ). Rates of falls $(17.8 \%$ versus $11.4 \%, P<0.001)$ and injuries (41.0\% versus $31.9 \%, P=0.005)$ were higher in patients with a positive tilt test. Prodromal symptoms (73.4\% versus $59.6 \%$, $P<0.001)$ and situational syncope were more frequent among patients with positive TT $(27.7 \%$ versus $16.2 \%, P<0.001)$. Therapy with nitrates was correlated with a lower TT positivity (Table 2).

CSM was positive in 103 patients (11.8\%), 21 of whom were younger than 65 years and 82 were older. The most frequent response to CSM was cardioinhibitory $(75.8 \%)$, followed by $16.5 \%$ with a vasodepressive response and $7.7 \%$ with a mixed response. The mixed response was more common in patients aged $<65$ years $(19 \%$ versus $4.9 \%, P=0.04)$, while cardioinhibitory and vasodepressive responses had a similar distribution in these two age groups. Positivity of CSM increased with advancing age, reaching a rate of $20 \%$ in the tenth decade (Figure 1B). Patients with positive CSM were older than those with negative CSM (73.6 \pm 12 versus
65.6 \pm 18 , respectively, $P<0.001$ ), and had a higher rate of falls $(22.3 \%$ versus $13.5 \%, P=0.002)$, pathologic ECG (43.7\% versus $24.8 \%, P<0.001)$, and left branch block $(5.3 \%$ versus $2.7 \%, P=0.002$ ). In multivariate analysis, predictors of positive CSM were advanced age and pathologic ECG (Table 2).

The rate of orthostatic hypotension increased with advancing age, reaching $24.3 \%$ in the eighth decade and $30.9 \%$ in the ninth decade (Figure 1C). The mean age of patients with orthostatic hypotension was higher $(73.3 \pm 14$ years versus $64.8 \pm 18$ years, $P=0.002$ ), and hypertension (66.1\% versus $48.1 \%, P<0.001)$, diabetes $(21.3 \%$ versus $12.3 \%, P=0.002)$, and varicose veins $(38.5 \%$ versus $19.7 \%$, $P<0.001)$ were also higher compared with patients without orthostatic hypotension. Patients with orthostatic hypotension had unexplained falls more frequently $(23.0 \%$ versus $12.5 \%$, $P=0.001)$ and were more likely to be taking hypotensive (66.1\% versus $49.1 \%, P<0.001)$ or antidepressant drugs (25.3\% versus $13.2 \%, P<0.001)$ than those without orthostatic hypotension. In multivariate analysis, predictors of orthostatic hypotension were varicose veins and treatment with alpha-receptor blockers, nitrates, or benzodiazepines (Table 2).

\section{Complex diagnosis}

One hundred and twenty-nine patients (23\% of the diagnoses) had a double diagnosis, ie, positivity in two of the three tests conducted. Compared with the rest of the patient population, this group of patients was older $(74.0 \pm 13$ versus
A

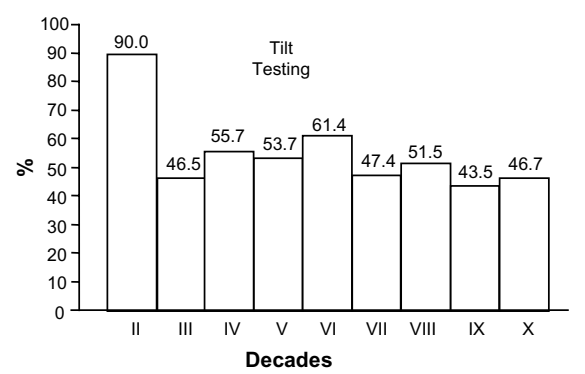

B

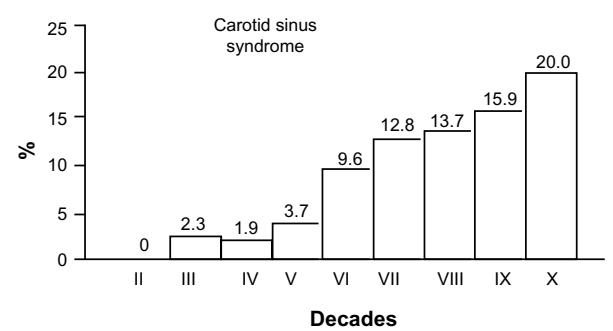

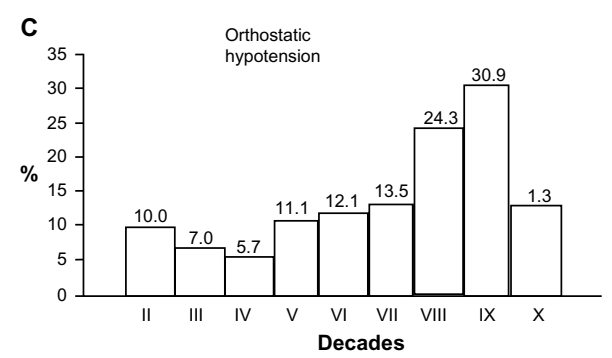

Figure I (A) Tilt test positivity, (B) carotid sinus syndrome, and (C) orthostatic hypotension in different age groups. 
Table 2 Predictors of neuroautonomic evaluation positivity in the multivariate analysis

\begin{tabular}{|c|c|c|}
\hline & HR (95.0\% Cl) & $P$-value \\
\hline \multicolumn{3}{|l|}{ Predictors of TT positivity } \\
\hline Prodromes & I.I (I.0-I.2) & 0.01 \\
\hline Situational syncope & I.I (I.0-I.I) & 0.003 \\
\hline Nitrates & $0.9(0.8-0.9)$ & 0.002 \\
\hline \multicolumn{3}{|l|}{ Predictors of CSS } \\
\hline Age (decades) & I.I (I.0-I.I) & 0.003 \\
\hline Pathologic ECG & I.0 (I.0-I.I) & 0.04 \\
\hline \multicolumn{3}{|l|}{ Predictors of $\mathrm{OH}$} \\
\hline Varicose veins & $1.13(1.06-1.21)$ & $<0.001$ \\
\hline Alpha-receptor blockers & $1.07(1.01-1.14)$ & 0.03 \\
\hline Nitrates & $1.08(1.01-1.16)$ & 0.01 \\
\hline Benzodiazepines & $1.12(1.04-1.20)$ & $<0.001$ \\
\hline
\end{tabular}

Abbreviations: $\mathrm{Cl}$, confidence interval; $\mathrm{ECG}$, electrocardiogram; $\mathrm{HR}$, hazard ratio; TT, tilt testing; CSS, carotid sinus syndrome; $\mathrm{OH}$, orthostatic hypotension.

$65.2 \pm 18, P<0.001)$, had a higher rate of hypertension $(59.7 \%$ versus $50.3 \%, P=0.04)$, varicose veins ( $32.6 \%$ versus $21.2 \%$, $P=0.01$ ), a pathologic ECG (34.9\% versus $25.7 \%, P=0.03$ ) and took more drugs, especially hypotensive agents $(60.5 \%$ versus $51.1 \%, P=0.05)$, such as alpha-receptor blockers (12.4\% versus $5.4 \%, P=0.005$ ). Patients aged 65 years or older had a higher rate of complex diagnosis. Predictors of double diagnosis in multivariate analysis were advanced age and treatment with alpha-receptor blockers and benzodiazepines (Table 3).

\section{Discussion}

The present study indicates the usefulness of the diagnostic protocol for syncope in the elderly population and reveals some peculiarities of neurally mediated syncope in older subjects. In total, 873 consecutive patients were enrolled in this study. A diagnosis was reached in 562 patients (64.3\%) with no significant differences in this regard between the two age groups (64.7\% in patients aged $<65$ years and $64.2 \%$ in patients $\geq 65$ years, $P=0.886$ ), confirming that also older patients can undergo neuroautonomic evaluation, as shown in the Italian Group for the Study of Syncope in the Elderly trial. ${ }^{8}$ In total, 684 patients (78.4\%) experienced almost two syncopal episodes, and 189 patients $(21.6 \%)$ had only one syncopal episode. Nevertheless, we performed neuroautonomic evaluation in these patients because of their high-risk

Table 3 Predictors of double diagnosis in multivariate analysis

\begin{tabular}{lll}
\hline & HR $(95.0 \% \mathrm{CI})$ & P-value \\
\hline Advanced age & $1.17(1.08-1.26)$ & $<0.001$ \\
Alpha-receptor blockers & $1.09(1.02-1.16)$ & $<0.001$ \\
Benzodiazepines & $1.07(1.01-1.14)$ & 0.003 \\
\hline
\end{tabular}

Abbreviations: $\mathrm{HR}$, hazard ratio; $\mathrm{Cl}$, confidence interval. situation (eg, absence of a prodrome, physical injury, or occupational implications). ${ }^{1}$ Neuroautonomic evaluation was performed in patients with only one syncopal episode, especially in the older population, because of the higher risk in patients older than 65 years.

\section{Neuroautonomic evaluation and age}

Tilt test positivity was similar across the decades. Multivariate analysis indeed showed that tilt test positivity was related to situational syncope and to the presence of prodromal symptoms. Nitrate therapy was associated with a lower tilt test positivity rate. These are new data, because in the literature there is still no mention of the possibility of an influence of medication on tilt test results. ${ }^{9}$ The supposition is that nitrates could interact with the administration of nitroglycerin during TT, reducing or nullifying the effect of nitrates, perhaps through a tolerance mechanism or tachyphylaxis. The presence of orthostatic hypotension increases with age, especially in the seventh and eighth decades, and is more often associated with varicose veins and therapy based on alpha-receptor blockers, nitrates, and benzodiazepines, all of which are frequently used in older people and to which more attention should be paid in order to reduce recurrence of syncope. ${ }^{10-12}$

CSM was positive in 103 cases (11.8\%), with $75.8 \%$ showing a cardioinhibitory response. CSS increased from $9.6 \%$ in patients aged $60-69$ years to $20 \%$ in patients aged 90-99 years. Multivariate analysis showed a cumulative 11\% rise in CSS probability for each age decade; ECG abnormalities were also related to an $8 \%$ rise in CSM, compared with a previous report suggesting that the only variables predicting a hypersensitivity response were male gender and age. ${ }^{13}$ Our incidence of CSS is similar to what was found in the Italian Group for the Study of Syncope in the Elderly ${ }^{8}$ and Evaluation of Guidelines in Syncope Study 2;14 but is lower than in the data reported by the Newcastle Syncope Unit in the UK, where each patient with syncope or an unexplained fall was evaluated with CSM; ${ }^{15,16}$ the incidence of CSS in the present study was $11.8 \%$, lower than what was observed in the study from Kerr et al in which however the CSM was preformed according to a non guideline-based technique. ${ }^{13}$

\section{Complex diagnosis and age}

There is mention in the literature of the coexistence of more than one diagnosis of syncope in the same subject, but these data came from numerically small populations, and also testing with old and outdated methods. ${ }^{17}$ In our study, 129 patients showed a double diagnosis after 
neuroautonomic evaluation (ie, positivity in two of the three tests conducted), in $10 \%$ of these cases it was tilt test + CSM in patients older than 65 years. However, it is frequent in clinical practice to incidentally find orthostatic hypotension in candidates for pacemaker implantation because of CSS. This is particularly important in the management of patients, especially for a reduction in syncope recurrence, which is demonstrated to be around 33\% in 2 years. ${ }^{2}$ The coexistence of more neurally mediated mechanisms can partly explain the high rate of relapse seen in a population for which an etiologic diagnosis of syncope was reached in more than $90 \%$ of cases. ${ }^{1}$ Moreover, orthostatic syncope after implantation of a pacemaker, if not explained or expected by the physician, could have an emotionally negative impact on the patient and their relatives.

The most frequent double diagnosis was the presence of orthostatic hypotension and tilt test positivity for vasovagal syncope in 89 patients (15.8\% of the diagnoses). The double diagnosis rate grew with increasing age, ie, $6.7 \%$ in the seventh decade and $20 \%$ in the tenth decade. With each decade of increasing age, there was a $17 \%$ rise in the probability of a double diagnosis. Other predictors of a double diagnosis were treatment with an alpha receptorblocker (HR 1.09, 95.0\% CI 1.02-1.16, $P=0.009$ ) and benzodiazepines (HR 1.07, CI 1.01-1.14, $P=0.03$ ). Sixteen patients $(2.8 \%)$ had a triple diagnosis; all were older or older elderly, and predictors of this association were decade of age (HR 1.07, CI 1.01-1.14, $P=0.04$ ) and presence of trauma (HR 1.07, CI 1.01-1.14, $P=0.04$ ).

\section{Conclusion}

This research confirms the importance of neuroautonomic evaluation both in patients aged $<65$ years and in those $\geq 65$ years with unexplained syncope after the initial evaluation. Further, it highlights for the first time to the author's knowledge the coexistence of different neurally mediated mechanisms in the genesis of syncope, especially in older people, and suggests a need to run a complete neuroautonomic evaluation in every patient, particularly older ones, without stopping at the first apparent etiologic diagnosis. Neuroautonomic evaluation is useful, safe, and well tolerated in older patients with syncope. The TT positivity rate is lower in patients chronically treated with nitrates, while varicose veins and treatment with alpha-receptor blockers and benzodiazepines are predictors of orthostatic hypotension. Positivity in two of the three tests performed is frequent in older people.

\section{Disclosure}

This paper is based on an analysis of data collected by the Syncope Unit, Cardiology and Geriatric Medicine, Azienda Ospedaliero Universitaria Careggi, Florence. The analyses described here are the responsibility of the authors alone and no mention is made of trade names, commercial products, or organizations. The authors report no conflicts of interest in this work.

\section{References}

1. Moya A, Sutton R, Ammirati F, et al. Guidelines for the diagnosis and management of syncope. Eur Heart J. 2009;30(21):2631-2671.

2. Ungar A, Galizia G, Morrione A, et al. Two-year morbidity and mortality in elderly patients with syncope. Age Ageing. 2011;40(6):696-702.

3. Del Rosso A, Ungar A, Bartoli P. Usefulness and safety of shortened head-up tilt testing potentiated with sublingual glyceril trinitrate in older patients with recurrent unexplained syncope. J Am Geriatr Soc. 2002;50(8):1324-1328.

4. Gieroba ZJ, Newton JL, Parry SW, Norton M, Lawson J, Kenny RA. Unprovoked and glyceryl trinitrate-provoked head-up tilt test is safe in older people: a review of 10 years' experience. J Am Geriatr Soc. 2004;52(11):1913-1915.

5. Del Rosso A, Bartoletti A, Bartoli P, et al. Methodology of head-up tilt testing with sublingual nitroglycerin in unexplained syncope. Am J Cardiol. 2000;85(8):1007-1011.

6. Puggioni E, Guiducci V, Brignole M, et al. Results and complication of the carotid sinus massage performed according to the "method of symptoms'. Am J Cardiol. 2002;89(5):599-601.

7. Davies AG, Kenny RA. Neurological complication following carotid sinus massage. Am J Cardiol. 1998;81(10):1256-1257.

8. Ungar A, Mussi C, Del Rosso A, et al. Diagnosis and characteristics of syncope in older patients referred to geriatric departments. J Am Geriatr Soc. 2006;54(10):1531-1536.

9. Biju P, Gieroba Z, Mangoni A. Influence of comorbidities and medication use on tilt table test outcome in elderly patients. Pacing Clin Electrophysiol. 2007;30(4):540-543.

10. Mader SL, Josephson KR, Rubenstein LZ. Low prevalence of postural hypotension among community dwelling elderly. JAMA. 1987;258(11):1511-1514.

11. Robbins AS, Rubenstein LZ. Postural hypotension in the elderly. J Am Geriatr Soc. 1984;32(10):769-771.

12. Mathias CJ, Kimber JR. Treatment of postural hypotension. J Neurol Neurosur Psychiatry. 1998;65(3):285-289.

13. Kerr SRJ, Pearce MS, Brayne C, Davis RJ, Kenny RA. Carotid sinus hypersensitivity in asymptomatic older persons. Arch Intern Med. 2006;166(5):515-520.

14. Brignole M, Menozzi C, Bartoletti A, Giada F, Lagi A, Ungar A. A new management of syncope: prospective systematic guidelinesbased evaluation of patients referred urgently to general hospitals. Eur Heart J. 2006;27(1):76-82.

15. Kenny RA, Richardson DA, Steen N. Carotid sinus syndrome: a modifiable risk factor for nonaccidental falls in older adults (SAFEPACE). J Am Coll Cardiol. 2001;38(5):1491-1496.

16. Davies AJ, Kenny RA. Falls presenting to the accident and emergency department: types of presentation and risk factor profile. Age Ageing. 1996;25(5):362-366.

17. McIntosh S, Da Costa D, Kenny RA. Outcome of an integrated approach to the investigation of dizziness, falls and syncope in elderly patients referred to a "syncope clinic". Age Ageing. 1993;22(1):53-58. 
Clinical Interventions in Aging

\section{Publish your work in this journal}

Clinical Interventions in Aging is an international, peer-reviewed journal focusing on evidence-based reports on the value or lack thereof of treatments intended to prevent or delay the onset of maladaptive correlates of aging in human beings. This journal is indexed on PubMed Central, MedLine, the American Chemical Society's 'Chemical Abstracts Ser-

vice' (CAS), Scopus and the Elsevier Bibliographic databases. The manuscript management system is completely online and includes a very quick and fair peer-review system, which is all easy to use. Visit $\mathrm{http}: / /$ www.dovepress.com/testimonials.php to read real quotes from published authors.

Submit your manuscript here: http://www.dovepress.com/clinical-interventions-in-aging-journal 